
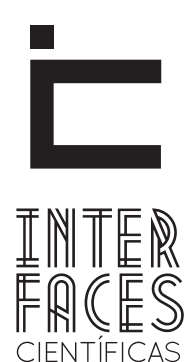

EDUCAÇÃO

ISSN IMPRESSO 2316-333X

E-ISSN 2316-3828

DOI-10.17564/2316-3828.2017v5n3p53-64

\title{
A FORMAÇ̧̃̃O INICIAL DE PROFESSORES DA EDUCAÇÃO INFANTIL E DE EDUCAÇÃO FÍSICA: A ARTICULAÇ̃̃O PEDAGÓGICA ENTRE AMBAS AS ÁREAS
}

\author{
THE INITIAL TRAINING OF TEACHERS OF EARLY CHILDHOOD EDUCATION AND PHYSICAL EDUCATION: THE PEDAGOGICAL \\ COORDINATION BETWEEN BOTH AREAS.
}

\section{LA FORMACIÓN INICIAL DE LOS PROFESORES DE EDUCACIÓN INFANTIL Y DE EDUCACIÓN FÍSICA: LA COORDINACIÓN PEDAGÓGICA ENTRE AMBAS ÁREAS}

\section{RESUMO}

Este artigo aborda a formação inicial dos professores Pedagogos e dos professores de Educação Física, com ênfase no desenvolvimento psicomotor de crianças da Educação Infantil, com idades entre três e cinco anos, a partir da cultura corporal de movimento. A escolha pela cultura corporal de movimento se justifica pelo entendimento de que o movimento humano não se restringe apenas num deslocamento, mas numa maneira de linguagem corporal em que expressamos sentimentos, emoções, aspectos culturais, dentre outros, contribuindo no desenvolvimento global das crianças. Os resultados desta pesquisa indicam a necessidade de se estruturar o trabalho interdisciplinar na Educação Infantil, contribuindo com o desenvolvimento das crianças e o preparo desses profissionais, desde suas formações iniciais.

\section{PALAVRAS-CHAVE}

Formação de professores. Educação infantil. Cultura corporal de movimento. Educação física. 


\section{ABSTRACT}

This article discusses the initial training of Educators teachers and physical education teachers, with an emphasis on psychomotor development of children from kindergarten, aged three and five years, from the culture of body movement. The choice of body culture movement is justified by the understanding that human movement is not restricted in displacement, but a way of body language we express feelings, emotions, cultural aspects, among others, contributing to the overall development of children. These results

\section{RESUMEN}

Este artículo aborda la formación inicial de maestros educadores y profesores de educación física, con un énfasis en el desarrollo psicomotor de los niños de jardín de infantes, de entre tres y cinco años, desde la cultura del movimiento del cuerpo. La elección del movimiento de cultura corporal se justifica por la comprensión de que el movimiento humano no se limita en el desplazamiento, sino una forma de lenguaje corporal expresamos sentimientos, emociones, aspectos culturales, entre otros, lo que contribuye al desarrollo integral de los niños. Estos resultados in- indicate the need to structure the interdisciplinary work in early childhood education, contributing to the development of children and preparing these professionals, since their initial training.

\section{KEYWORDS}

Teacher training. Early childhood education. Culture of body movement. Physical education. dican la necesidad de estructurar el trabajo interdisciplinario en la educación infantil, contribuyendo al desarrollo de los niños y la preparación de estos profesionales, ya que su formación inicial.

\section{PALABRAS CLAVE}

Formación del profesorado. La educación de la primera infancia. La cultura del movimiento corporal. Educación física. 


\section{INTRODUÇ̃̃̃o}

Ao nos referimos à formação dos professores da Educação Infantil e da Educação Física, identificando aspectos da formação inicial de ambos, visamos destacar a importância da articulação dos seus trabalhos dentro da escola.

Dessa forma, este artigo vem ligar a ação pedagógica dos professores da Educação Infantil (Pedagogos) e os da Educação Física aos conceitos da teoria histórico-cultural e da cultura corporal de movimento, bem como os aspectos psicomotores, como objeto de trabalho e de possibilidade ao desenvolvimento infantil, em específico com as crianças com idades entre três e cinco anos.

Ao compreendermos que o movimento humano faz parte da área de conhecimento da Educação Física Escolar em toda a Educação Básica, espera-se que esse profissional possa ser o responsável por ministrar as aulas de Educação Física na Educação Infantil. Em contrapartida, os Pedagogos são os responsáveis, em muitas instituições, por trabalhar esses aspectos do desenvolvimento com as crianças. Em nosso capítulo discutiremos, então, se os referidos profissionais estão, ou não, preparados para isso.

Assim, destaca-se

[...] a questão da especificidade do professor de EF na Educação Infantil, sendo necessário, como salienta Sayão (1999), romper com as barreiras que determinam o que é específico de cada área de conhecimento e abrir espaço para uma atuação integrada dos diferentes profissionais que lidam com as crianças pequenas que, de forma isolada, não conseguem construir um trabalho voltado para as reais necessidades do mundo infantil. 0 problema não está na atuação dos diversos profissionais na Educação Infantil, mas sim em concepções de trabalho pedagógico que geralmente fragmentam as funções de uns e outros, isolando cada um em seu campo. (COSTA; LACERDA, 2012, p. 329).

Baseamo-nos em autores que tratam da formação de professores (áreas da Pedagogia e da Educação Física), além daqueles voltados ao movimento humano em relação ao desenvolvimento infantil, com base em uma visão crítica de educação, de homem e de sociedade.

\section{EDUCAÇÃO INFANTIL: FORMAÇÃO INICIAL DO PROFESSOR}

Em termos legais, o professor da Educação Infantil deve ser graduado, licenciado e habilitado para tal. 0 curso de Pedagogia, por exemplo, a partir de informações do Ministério da Educação (BRASIL, MEC),

[...] é um curso superior de graduação, na modalidade de licenciatura e tem como finalidade formar professores para atuar na Educação Infantil e nos anos iniciais do Ensino Fundamental (até o Quinto Ano). É aquele professor que assume integralmente o currículo da série $[\ldots]$.

Independentemente do tipo de estrutura do curso de Pedagogia, um ponto fundamental de destaque é

[...] que as instituições ou cursos de preparação para a formação inicial deveriam ter um papel decisivo na promoção não apenas do conhecimento profissional, mas de todos os aspectos da profissão docente, comprometendo-se com o contexto e a cultura em que esta se desenvolve. Devem ser instituições "vivas", promotoras da mudança e da inovação. (IMBERNÓN, 2004, p. 61).

Isso porque, a criança se desenvolve por meio da exploração do meio em que vive, da relação que possui entre adultos e outras crianças no seu convívio e dos conhecimentos e valores a ela ensinados, principalmente nas brincadeiras. A criança é um ser ativo e possuidor de conhecimentos prévios, oriundos a partir de suas interações sociais dentro e fora da escola.

$\mathrm{Na}$ evolução do processo de ensino e aprendizagem dentro da escola, cabe ao professor estabelecer os conteúdos a serem trabalhados e suas metodologias, mediante o perfil do seu público. Entretanto, só haverá um resultado positivo se esse profissional for detentor de uma formação inicial sólida e que apresente os conceitos do desenvolvimento humano a serem trabalhados na escola, de modo interdisciplinar e pautado nas experiências que seus alunos trazem do meio em que estão inseridos.

Para auxiliar no trabalho docente com os alunos da Educação infantil, o Ministério da Educação (MEC) 
organizou o Referencial Curricular Nacional para a Educação Infantil (RCNEI), que é um documento orientador, dividido em três volumes:

- Volume I: Introdução;

- Volume II: Formação pessoal e social;

- Volume III: Conhecimento de mundo.

O RCNEI é um documento oficial não normativo e deve ser entendido como uma proposta aberta, flexível e não obrigatória, que visa à estruturação das propostas educacionais adequadas à especificidade de cada público atendido pela Educação Infantil. A elaboração do referido documento é feita com base na Lei de Diretrizes e Bases da Educação Nacional (LDBEN). Em específico, no terceiro volume, há o destaque ao movimento como sendo um fator importante no desenvolvimento humano e cultural.

[...] Ao movimentar-se, as crianças expressam sentimentos, emoções e pensamentos, ampliando as possibilidades do uso significativo de gestos e posturas corporais. O movimento humano, portanto, é mais do que simples deslocamento do corpo no espaço: constitui-se em uma linguagem que permite às crianças agirem sobre o meio físico e atuarem sobre o ambiente humano, mobilizando as pessoas por meio de seu teor expressivo. (BRASIL, 1998, p. 16).

Ao vermos a importância que é dada ao movimento pelo RCNEl, destacamos a formação inicial do professor que irá trabalhar com as crianças de zero a cinco anos de idade. Isso porque o movimento é fundamental na aprendizagem, quando trabalhado com embasamento nos pressupostos da psicomotricidade e dos conhecimentos e das experiências que as crianças trazem para a escola.

Justificando, Imbernón (2004, p. 66) ressalta que:

O currículo formativo para assimilar um conhecimento profissional básico deveria promover experiências interdisciplinares que permitissem ao futuro professor ou professora integrar os conhecimentos e os procedimentos das diversas disciplinas (ou disciplina) com uma visão psicopedagógica (integração e relação do conhecimento didático do conteúdo com o conhecimento psicopedagógico).
Por meio desse currículo formativo (coerência entre a organização e as normas dos sistemas de ensino e de formação profissional), o professor precisa entender que a criança não é um adulto em miniatura. Ela possui características próprias e necessita de mediações para que seu desenvolvimento ocorra. Desde seu nascimento, começa a ter as influências da família e das pessoas com as quais convive e, posteriormente, esse grupo se expande com seus pares e professores na escola.

Um dos meios para que esse desenvolvimento ocorra na escola, especificamente na Educação Infantil, é por meio da brincadeira. Brincando a criança compara, analisa, nomeia, associa, classifica, conceitua e cria. 0 brinquedo e a brincadeira traduzem o mundo que a criança vê e faz parte da sua realidade, possibilitando o seu desenvolvimento e influenciando diretamente na aprendizagem. Por isso a brincadeira deve ser entendida como componente da Educação Infantil, para que auxilie no processo de ensino e aprendizagem dos alunos.

Esse caminho só será possível se trilhado a partir da formação do professor.

\footnotetext{
Para que a educação infantil cumpra essa função, não poderá haver um distanciamento entre a ação mediadora, que é a atividade desenvolvida pelo educador, e as condições necessárias para o desenvolvimento e constituição do gênero humano, pela criança. (ALMADA, 2011, p. 62).
}

Quando nos referimos ao brincar, não estamos restringindo a ação educativa dos professores apenas ao uso de objetos (brinquedos). Pode-se trabalhar, também, a psicomotricidade por meio de brincadeiras com e sem objetos, que é outro componente fundamental da aprendizagem, assim como afirma Rocha (2000), dizendo que a atividade lúdica está ligada aos objetos, às ações e à mediação social.

Cabe ao professor intervir para que as crianças alcancem o estado de integração e conhecimento corporal, possibilitando confiança em seus atos mediante a valorização do seu próprio corpo e de suas limitações. 
A Educação Infantil merece um componente curricular - Movimento - que tenha como pressupostos o desenvolvimento da criança por inteiro, não a dicotomizando em corpo e pensamento, em capacidades físicas e cognição. Além disso, as crianças necessitam de um trabalho com Movimento direcionado às suas vidas, engajado no trabalho dos demais componentes curriculares da Educação Infantil, para que ela possa ver a relação da Educação Física com a sua vida, com a aquisição de conhecimentos e não apenas a relação com o esporte e saúde. (MELLO, 2000, p. 5 apud FERREIRA; FREITAS, 2011, p. 9).

É importante que o professor tenha esse entendimento de que a separação entre corpo e mente e/ou teoria e prática não acontece de maneira fragmentada no processo educativo. A relação professor-aluno deve acontecer de modo compreensivo, especialmente do primeiro em relação ao segundo, favorecendo a realização das ações em um ambiente acolhedor, agradável, seguro e prazeroso às crianças.

As práticas pedagógicas inadequadas ou incoerentes às faixas etárias dos alunos, a falta de exploração de atividades psicomotoras e do aproveitamento das vivências que os alunos trazem para dentro da escola são consequências da falta de conhecimento e/ou lacunas na formação inicial, no que se refere aos diferentes aspectos do desenvolvimento infantil e, em especial, à atividade motora.

0 professor precisa entender os conceitos da cultura corporal de movimento e como irá utilizá-la e desenvolvê-la durante o processo de aprendizagem, permitindo que os alunos experimentem e se apropriem de conhecimentos do mundo ao seu redor, sendo um mediador e não um mero interventor. Entretanto, sem um embasamento, um conhecimento prévio e coeso, a observação e a mediação nas ações das crianças durante as brincadeiras deixarão de lado a essência do processo de ensino e aprendizagem. E essa base precisa fazer parte da formação inicial dos professores da Educação Infantil.

Essa preocupação quanto à formação do Pedagogo se reflete no entendimento da legislação sobre a educação (LDB), pois, desde 1996 a Educação Infantil passou a integrar a Educação Básica. Esta possui a
Educação Física como disciplina obrigatória em todos os seus segmentos, inclusive na Educação Infantil, como vemos:

\begin{abstract}
Apesar de não estar contemplada no Referencial Curricular Nacional para a Educação Infantil, tal como a Música e Artes, a Educação Física tornou-se obrigatória na Educação Básica, quando a lei n 10.328 de 12 de dezembro de 2001 introduziu a palavra "obrigatório" após a expressão "curricular", alterando o parágrafo $3^{\circ}$ do art. 26 da lei $n^{\circ}$ 9.394 de 20 de dezembro de 1996, Lei de Diretrizes e Bases da Educação Nacional: "A educação física, integrada à proposta pedagógica da escola, é componente Curricular obrigatório da Educação Básica, ajustando-se às faixas etárias e às condições da população escolar, sendo facultativa nos cursos noturnos". Porém, não há dados no MEC sobre o cumprimento de tal determinação legal. (GONÇALVES, 2014, p. 3).
\end{abstract}

A partir dessa citação podemos entender que a Educação Física deveria fazer parte do currículo da Educação Infantil, como disciplina obrigatória. Entretanto, a presença facultativa do professor especialista coloca para o Pedagogo a responsabilidade de trabalhar todos os conteúdos relacionados ao movimento humano, psicomotricidade, dentre outras atividades corporais, mesmo que este não tenha essa formação específica e ou não tenha um suporte teórico em sua formação inicial. Ressaltamos, também, assim como Ferreira e Freitas (2011), que o outro fator desfavorável à formação inicial dos professores (Educação Infantil e Educação Física) está no próprio RCNEI, quando aborda o conteúdo "movimento", provocando uma fragmentação do trabalho pedagógico em relação a esse conteúdo, onde a especificidade se sobrepõe ao conhecimento.

\subsection{A FORMAC̄̃O INICIAL DO PROFESSOR DE EDUCAÇ̃̃o FÍSICA E A EDUCAÇÃO INFANTIL}

\footnotetext{
Ao se pensar o corpo, pode-se incorrer no erro de encará-lo como puramente biológico, um patrimônio universal sobre o qual a cultura escreveria histórias diferentes. [...] Entretanto, [...] existe um conjunto de significados que cada sociedade escreve nos corpos dos seus membros ao longo do tempo, significados estes que definem o que é corpo de maneiras variadas. (DAOLIO, 2000, p. 36).
} 
Ao pensarmos na formação de professores de Educação Física (EF), suas práticas pedagógicas norteiam e direcionam o seu trabalho, como uma das perspectivas mais relevantes e importantes. Nesse sentido, "é no contexto da escola que o docente constrói a sua profissão" (NÓVOA, 1995, p. 25).

Ele tem a possibilidade de constituir um núcleo de formação, sendo um espaço de discussão e de ação, por meio de um processo de reflexão sobre o que e como fazer; torna-se capaz de dar respostas às necessidades surgidas a partir das análises da prática docente. A “formação não se constrói por acumulação (de cursos, conhecimentos, ou técnicas), mas, sim, mediante um trabalho de reflexividade crítica sobre as práticas e de reconstrução permanente de uma identidade pessoal" (NÓVOA, 1995, p. 25).

0 professor de EF licenciado está habilitado a trabalhar na escola em todos os segmentos da Educação Básica, colaborando e auxiliando no processo de ensino e de aprendizagem dos alunos. Em específico, na Educação Infantil, a presença desse profissional é de suma importância, colaborando com o trabalho do Pedagogo, pois, de acordo com a lei de diretrizes e bases da educação nacional (LDBEN - 1996), a EF deve fazer parte do projeto pedagógico da escola e deve se adequar às especificidades dos diferentes alunos atendidos.

Entretanto, não estamos afirmando que o professor de EF irá trabalhar somente o movimento, as ações mecânicas e fisiológicas do corpo e o Pedagogo, por sua vez, de forma segregada, trabalhará somente com o desenvolvimento intelectual e cognitivo das crianças. Consideramos que essa dicotomia poderá deixar de existir a partir da formação dos professores de ambas as áreas da discussão, em que sejam embasados pelo entendimento do desenvolvimento infantil a partir das relações, das experiências, das vivências e dos estímulos a que as crianças precisam ter acesso, especificamente na Educação Infantil ou, ainda, de zero a cinco anos de idade. Ayoub (2001 apud FERREIRA, 2010) justifica essa concepção, em que os professores não deveriam se situar como especialistas de determinadas áreas, mas entendendo o movimento corporal como uma maneira de linguagem dos seres humanos, desenvolvida ao longo de uma trajetória histórica.
Freire e Scaglia (2003) destacam e reforçam que a divisão do conteúdo em áreas de conhecimento não deve ser o foco principal na EF, mas sim o desenvolvimento do indivíduo em um ambiente humano, sob a luz dos aspectos cultural e social; o currículo escolar precisa apontar soluções para a vida social.

Corroborando, Faria Júnior (1999, p. 227) diz que:

[...] De um lado, percebe-se a tendência de manter e reproduzir os padrões tradicionais de valores, pensamento e organização. De outro lado, a tendência de promover mudanças. Admite-se que a natureza conflitante do campo de formação profissional justifica-se pelo fato de a própria sociedade apresentar tendências contraditórias.

Precisamos nos ater ao fato de que a escola, em especial, na Educação Infantil, é um local de novas descobertas e de trocas de experiências para a criança, fora do ambiente familiar. 0 professor de EF tem a possibilidade de oferecer aos alunos inúmeras opções de novas experiências e apropriação daquelas que eles trazem consigo, por meio de situações em que seja necessário criar, inventar, descobrir novos movimentos e gerar novos conceitos e ações sobre o movimento humano (conhecimento corporal, limitações, desafios motores e intelectuais, trocas sociais etc.), utilizando a linguagem corporal, o que contribui para o desenvolvimento das crianças.

Daí a importância na formação do professor de EF, para que ele consiga atingir esses objetivos durante o seu trabalho com crianças de até cinco anos de idade, especificamente por meio da cultura corporal de movimento.

Nessa perspectiva da reflexão da cultura corporal, a expressão corporal é uma linguagem, um conhecimento universal, patrimônio da humanidade que igualmente precisa ser transmitido e assimilado pelos alunos na escola. A sua ausência impede que o homem e a realidade sejam entendidos dentro de uma visão de totalidade. [...]. (COLETIVO..., 2001, p. 42).

O professor de EF na Educação Infantil tem a função de orientar, mediar e colaborar com a construção do conhecimento dos alunos, organizando as ações pedagógicas para que possibilitem a interação entre 
os sujeitos (crianças) e o mundo (ambiente em que estão inseridos) para que possam agir de modo emancipado e autônomo.

Como afirmam Freire e Scaglia (2003), para construirmos nossa cultura precisamos da capacidade de aprendizagem e de adaptação ao novo e à construção e criação de novos recursos, além de sermos flexíveis, com nossas habilidades sempre acessíveis e disponíveis às modificações necessárias. "No corpo estão inscritas todas as regras, todas as normas e todos os valores de uma sociedade específica, por ser ele o meio de contato primário do indivíduo com o ambiente que o cerca." (DAOLIO, 2000, p. 39).

A EF na Educação Infantil ajudará a proporcionar resultados positivos no processo de ensino-aprendizagem como um todo no desenvolvimento dos alunos. 0 seu trabalho pedagógico irá se pautar na relação entre o pensamento e a ação, assegurando o desenvolvimento global, de acordo com as possibilidades das crianças. Será por meio dessa ação sobre o meio físico com o meio social e da interação como ambiente social que ocorrerão o desenvolvimento e a aprendizagem.

É um processo complexo, que produz transformações qualitativas pela combinação de fatores biológicos, psicológicos e sociais. O professor de EF, entretanto, precisa estar sempre atento às etapas do desenvolvimento do aluno, colocando-se no papel de mediador da aprendizagem, atuando em conjunto com o pedagogo, proporcionando uma prática pedagógica embasada em uma relação de coerência e coesão, não acontecendo de maneira fragmentada.

$O$ processo de ensino e de aprendizagem na EF, portanto, não se restringe ao desenvolvimento de certas habilidades e destrezas, mas em capacitar a criança para refletir sobre suas possibilidades corporais e, de forma autônoma, exercê-las de maneira social e culturalmente significativas. Assim, o professor de EF que atua na Educação Infantil não deve possuir apenas conhecimentos específicos de sua área, porém somá-los aos conhecimentos da criança com a qual está trabalhando.

É necessário, também, que entendamos que o aluno da Educação Infantil apresenta como principal característica à necessidade de movimentos. Assim, destaca-se a importância de se tratar e de se compreender o movimento humano, que é uma das especificidades da EF. Isso não quer dizer que o processo metodológico da EF na Educação Infantil só irá focar o movimento, entretanto é preciso que o professor se aproprie e respeite os conhecimentos que a criança traz do seu meio social para dentro da escola, explorando os aspectos cognitivos, sociais, afetivos e motores de maneira integrada e equilibrada.

\begin{abstract}
O homem, por meio do seu corpo, vai assimilando e se apropriando dos valores, normas e costumes sociais, num processo de incorporação (a palavra é significativa). [...] Mais do que um aprendizado intelectual, o indivíduo adquire um conteúdo cultural, que se instala no seu corpo, no conjunto de suas expressões. Em outros termos, o homem aprende a cultura por meio do seu corpo. (DAOLIO, 2000, p. 39).
\end{abstract}

O movimento e a expressão corporal são meios pelos quais as crianças se comunicam com seus pares e estabelecem suas relações com o mundo adulto, criando bases para a construção do conhecimento sobre as coisas, e o trabalho do professor de EF se justifica como um colaborador do seu desenvolvimento. Porém seu trabalho, dentro da Educação Infantil, não deverá estar somente direcionado à aquisição de normas, condutas e de hábitos padronizados, ou de preparação para o ciclo educacional seguinte (Ensino Fundamental), mas entender e se apropriar das potencialidades que as crianças trazem consigo de uma maneira interdisciplinar e sem rupturas com os objetivos da Educação Infantil.

Além disso, se faz necessário repensar a ideia da EF como isolamento e pensá-la em uma relação transdisciplinar, favorecendo a interligação dos saberes. A complexidade é a união do conhecimento específico na interligação com os demais saberes, diferenciando-se das definições reducionistas, que só percebem o objeto de sua disciplina. "A complexidade encontra-se justamente no âmago da relação entre o simples e o complexo porque tal relação é ao mesmo tempo antagônica e complementar" (MORIN, 2005, p. 125). 
Será por meio dessa articulação de conhecimentos e de saberes que irão se constituir os conhecimentos nas crianças, em uma relação de cooperação e, ao mesmo tempo, de antagonismos.

Ao considerarmos a necessidade de preparo quanto à formação inicial do professor de EF, especificamente para a Educação Infantil, destacamos a necessidade pedagógica de maior domínio conceitual, por um processo de afirmação ao qual o professor se perceba como aquele que é capaz de produzir conhecimento e não somente um reprodutor de conhecimentos já prontos. Destacamos, também, a devida importância a ser destinada ao movimento humano na Educação Infantil, pois

\begin{abstract}
[...] a educação motora distancia-se da educação física tradicional, pois esta é mais mecanicista, com visão cartesiana/newtoniana, no momento que se separa corpo/mente e preocupa-se mais com o resultado, pois liga-se geralmente à forma técnica da execução de modelos estereotipados, organizados na composição de tempos e repetições. (TOJAL, 2004, p. 143).
\end{abstract}

Assim, é preciso que o professor de EF entenda e compreenda a concepção de criança, a sua presença na Educação Infantil e, também, considerar que a criança possui seus próprios conhecimentos advindos dos aspectos históricos e culturais, construídos por meio de sua interação com diferentes grupos/pessoas antes de iniciar sua experiência na escola.

O pensamento infantil não está diretamente voltado ao futuro, a criança vive o agora, o presente. Daí acontece a diferenciação de uma criança para outra, tornando a prática pedagógica na Educação Infantil uma ação com maior necessidade de reflexão e de atenção por parte dos profissionais que junto dela atuam.

\section{MOVIMENTO HUMANO NA EDUCAÇÃO INFANTIL}

O movimento faz parte da vida humana, pois desde o nascimento as crianças se movimentam. Entretanto, 0 movimento humano não se restringe somente ao deslo- camento e/ou à locomoção, mas numa forma de linguagem corporal em que expressamos nossos sentimentos, nossas emoções e nossos pensamentos. Esse processo de como ocorre o movimento é resultado da interação do homem com o meio, pelas interações sociais e por meio da cultura a qual a criança está inserida e faz parte.

Ao brincar, jogar, imitar e criar ritmos e movimentos, as crianças também se apropriam do repertório da cultura corporal na qual estão inseridas.

\begin{abstract}
O movimento para a criança pequena significa muito mais do que mexer partes do corpo ou deslocar-se no espaço. A criança se expressa e se comunica por meio dos gestos e das mímicas faciais e interage utilizando fortemente o apoio do corpo. A dimensão corporal integra-se ao conjunto da atividade da criança. Pode-se dizer que no início do desenvolvimento predomina a dimensão subjetiva da motricidade, que encontra sua eficácia e sentido principalmente na interação com o meio social, junto às pessoas com quem a criança interage diretamente. A externalização de sentimentos, emoções e estados íntimos poderão encontrar na expressividade do corpo um recurso privilegiado. (RCNEI, 1998, p. 18).
\end{abstract}

Por meio do movimento, a criança conhece mais sobre si e sobre o outro (seus pares), aprendendo a relacionar-se; é parte integrante da construção da autonomia e da identidade, pois contribui para o domínio das habilidades motoras que a criança desenvolve ao longo da sua infância.

Porém, é preciso abolir a concepção de que existem formas gestuais ideais e específicas e determinadas a cada faixa etária, únicas, padronizadas que a criança deva aprender. Cada criança é única e possui suas características, principalmente ao nos referirmos ao movimento humano. Essa é uma das funções dos professores (EF e Pedagogo), que durante suas práticas pedagógicas devem entender e enxergar as crianças como seres sociais, que possuem uma história e que fazem parte de um meio sociocultural. Isso porque

[...] analisar as representações que os professores possuem, tanto a respeito do corpo como a respeito de sua prática profissional, apresenta-se como importante tarefa quando se objetivam a reciclagem desses profissionais e a consequente qualificação do seu trabalho. (DAOLIO, 2000, p. 49). 
Embora deixe algumas lacunas quando trata do movimento na Educação Infantil, o RCNEI aponta metas de qualidade que contribuem para que as crianças tenham um desenvolvimento integral de suas identidades. Visa, também, contribuir para que possa realizar, nas instituições que oferecem a Educação Infantil, o objetivo socializador dessa etapa educacional, em ambientes que propiciem o acesso e a ampliação, pelas crianças, dos conhecimentos da realidade social e cultural. Assim,

[...] o movimento é uma forma expressiva relevante para as crianças; logo, todos os educadores têm a obrigatoriedade de compreendê-lo. Muito além de um olhar biológico ou fisiológico, o corpo que corre e cresce é o mesmo que sente, conhece e se expressa. Portanto, para uma compreensão mais apurada da motricidade infantil faz-se necessária aos profissionais que atuam na escola. (NEIRA; MATTOS, 2008, p. 11).

Em um trabalho pedagógico que pretende articular a EF ao trabalho do Pedagogo, "[...] a educação física teria por finalidade preservar a condição natural humana das crianças, estimulando suas habilidades motoras e seu desenvolvimento corporal e libertando-a do jugo do contrato social representado pela escola tradicional" (DAOLIO, 2007, p. 28).

À medida que a criança cresce, o desenvolvimento de novas capacidades possibilita que ela atue de maneira mais independente sobre o mundo ao seu redor, adquirindo maior autonomia em relação às influências e interferências dos adultos. Assim, cabe aos professores compreenderem que

[...] o movimento não acontece sozinho. Não há movimento pelo movimento. Toda ação tem uma intenção. É o que caracteriza o seu aspecto comunicativo, determinado sempre pelo contexto cultural onde está inserido. Qualquer gesto tem como suporte um significado [...]. (MATTOS; NEIRA, 2008, p. 5).

Atentamos para a análise de que o movimento na Educação Infantil se dá, principalmente, por meio do brinquedo e da brincadeira, em que os atos motores são essenciais às crianças, além da exploração de ati- vidades simbólicas. Em contrapartida, a criança tem influências do mundo real, concreto, com o qual ela se relaciona e vive.

A presença da EF na Educação Infantil objetiva atender às necessidades e expectativas das crianças, obtendo uma melhor compreensão sobre o que realmente a criança necessita, a partir de suas características de crescimento e de desenvolvimento, pois é importante “[...] analisar as representações que os professores possuem, tanto a respeito do corpo como a respeito de sua prática profissional. [...]" (DAOLIO, 2000, p. 49).

Para isso, vemos que o movimento é fundamental à criança e, quando nos referimos à Educação Infantil como uma etapa do desenvolvimento das crianças e tendo uma função educativa, o papel dos professores que atendem essas crianças deve ser revisto e repensado, tanto no aspecto de formação inicial destes como em suas práticas pedagógicas.

No entanto, na Educação Infantil, os conteúdos relacionados ao corpo e ao movimento estimulam a percepção e a consciência corporal da criança; desenvolvem noções de espaço, a individualidade e a coletividade no movimento, a socialização; a percepção do seu próprio ritmo e com o outro. Dessa forma, a capacidade de pensar, de criar, de enfrentar situações e de resolver problemas está intrínseca nessas atividades.

É nesse sentido que a compreensão do ser humano corresponde, em se considerar a sua totalidade, na qual todas as dimensões (física, intelectual, psicológica, ética, afetiva, moral, social e cultural) se complementam. Isso se dá por meio de como as relações e as interações que estabelecemos com o outro e com o mundo influenciam e contribuem em nossa formação, como indivíduos sociais e culturais.

\section{CONSIDERACÕ̃ES FINAIS}

A Educação Infantil é a primeira etapa da Educação Básica e, dessa forma, tem como finalidade o desenvolvimento integral das crianças. Nessa etapa, elas começam a construir suas experiências motoras, unindo os movimentos construídos por 
elas, com aqueles culturais e sociais que cada uma possui, considerando que esta construção depende dos recursos biológicos, psicológicos e condições do meio em que vivem, além da mediação e dos estímulos oferecidos.

Valorizar o movimento corporal na Educação Infantil é inserir e aproveitar o caráter lúdico do movimento humano em benefício de um desenvolvimento significativo. 0 corpo é um elemento mediador da aprendizagem e do desenvolvimento humano; a educação pelo movimento é parte fundamental no processo de aprendizagem.

O professor de EF não deve possuir somente conhecimentos específicos da sua área, mas agregá-los aos conhecimentos das crianças e aos do Pedagogo. Com essa articulação e integração de conhecimentos, o trabalho do movimento humano na Educação Infantil apresentará um melhor resultado ao desenvolvimento das crianças e, também, será justificada a importância da presença da EF, como parte indissociável a este processo, na Educação Infantil.

\section{REFERÊNCIAS}

\section{ALMADA, Francisco de A.C. de. A formação do professor de educação infantil no curso de pedagogia de um centro universitário: uma análise a partir da teoria histórico-cultural. Marília, 2011. Disponível em: <www.marilia.unesp.br/Home/Pos-Graduacao/ Educacao/Dissertacoes/almada_fac_do_mar.pdf $>$. Acesso em: 19 abr. 2015.}

AYOUB, E. Reflexões sobre a educação física na educação infantil. Revista Paulista de Educação Física. São Paulo, supl.4, p.53-60, 2001.

\section{BRASIL. Lei de Diretrizes e Bases da Educação}

Nacional - Lei n. 9.394/96. Disponível em: <www. planalto.gov.br/ccivil_03/leis/l9394.htm>. Acesso em: 3 mar. 2015.
BRASIL. Ministério da Educação e do Desporto. Secretaria de Educação Fundamental. Referencial Curricular Nacional para a Educação Infantil. Brasília: MEC/SEF, v.3, 1998.

\section{COLETIVO DE AUTORES. Metodologia do ensino da} educação física. 8.ed. São Paulo: Cortez, 2001.

COSTA, Martha B. da; LACERDA, Cristiane G. de. Educação Física na Educação Infantil e o currículo da formação inicial. Revista Brasileira de Ciências do Esporte, Florianópolis, v.34, n.2, p.327-341, abrjun. 2012. Disponível em: <www.scielo.br/pdf/rbce/ v34n2/a06v34n2.pdf>. Acesso em: 30 set. 2015.

DAOLIO, Jocimar. Da cultura do corpo. 5.ed. Campinas: Papirus, 2000.

DAOLIO, Jocimar. Educação física e o conceito de cultura. 2.ed. Campinas: Autores Associados, 2007.

FARIA JÚNIOR, Alfredo G. de. Perspectivas na formação profissional em educação física. In: MOREIRA, Wagner Wey (Org.). Educação física e esportes: perspectivas para o século XXI. 4.ed. Campinas: Papirus, 1999.

\section{FERREIRA, Maria C.P. de L. Ensino do conceito de} movimento corporal na perspectiva históricocultural de Davydov. Goânia, 2010. Disponível em: <http://tede.biblioteca.ucg.br/tde_busca/arquivo. php?codArquivo=1075>. Acesso em: 1 abr. 2015.

FERREIRA, Maria C.P. de L.; FREITAS, Raquel Ap. M. de M. 0 lugar da educação física na educação infantil. IV EDIPE - Encontro Estadual de Didática e Prática de Ensino, 2011. Disponível em: <www.ceped. ueg.br/anais/ivedipe/pdfs/educacao_fisica/co/383865-1-SM.pdf>. Acesso em: 19 abr. 2015.

FREIRE, João B.; SCAGLIA, Alcides J. Educação como prática corporal. São Paulo: Scipione, 2003. 
GONÇALVES, Roberta de Sá. Educação física e a educação infantil: acesso de poucos ao direito de todos. Conteúdo Jurídico. Brasília-DF, 2014. Disponível em: <www.conteudojuridico.com. br/?artigos\&ver $=2.47026 \&$ seo $=1>$. Acesso em: $20 \mathrm{abr}$. 2015.

\section{IMBERNÓN, Francisco. Formação docente e}

profissional: formar-se para a mudança e a incerteza. 4.ed. São Paulo: Cortez, 2004.

MATTOS, Mauro. G.; NEIRA, M.G. Educação física infantil: construindo o movimento na escola. 7.ed. São Paulo: Phorte, 2008.
MORIN, Edgar. Introdução ao pensamento complexo. Porto Alegre: Sulina, 2005.

NÓVOA, Antônio. Os professores e sua formação.

2.ed. Portugal: Dom Quixote, 1995.

ROCHA, Maria Silvia P. de M.L. da. Não brinco mais: a (des)construção do brincar no cotidiano educacional. ljuí: UNIJUÍ, 2000.

TOJAL, João B.A.G. Educação motora: que profissional formar? In: DE MARCO, Ademir (Org.). Pensando a educação motora. 3.ed. Campinas: Papirus, 2004.
Recebido em: 28 de novembro de 2015 Avaliado em: 14 de julho de 2016 Aceito em: 05 de novembro de 2016
1 Mestre em Educação - Formação de professores e práticas pedagógicasPontifícia Universidade Católica da Campinas- PUCCAMP; Graduado em Educação Física (Licenciatura Plena) - UNIPINHAL; Licenciatura em Pedagogia - FALC; Especialização em Educação Física Escolar pela Universidade Gama Filho. E-mail: r_taveira@ig.com.br

2 Professora/Pesquisadora Titular, em regime de dedicação integral, do Programa de Pós-Graduação em Educação da Pontifícia Universidade Católica de Campinas - PUCCAMP; Atua na linha de pesquisa Formação de Professores e Práticas Pedagógicas e integra o grupo de pesquisa Formação e Trabalho Docente; Mestre (2000) e doutorado em Educação pela Universidade Metodista de Piracicaba (2005), com estágio de doutorado em Formação de Professores de Educação Infantil no exterior, na Universidade de Aveiro/Portugal. E-mail: hhazevedo79@gmail.com 
